\title{
Prostate Small Cell Carcinoma and Skin Metastases: A Rare Entity
}

\author{
Yesim Yildirim ${ }^{a}$ Yesim Akcay ${ }^{b}$ Ozgur Ozyilkan ${ }^{a}$ Bulent Celasun ${ }^{c}$ \\ Departments of ${ }^{a}$ Medical Oncology ${ }^{b}$ Internal Medicine and ${ }^{\mathrm{c} P a t h o l o g y, ~ B a s k e n t ~ U n i v e r s i t y, ~ A n k a r a, ~ T u r k e y ~}$
}

\section{Key Words}

Prostate carcinoma $\cdot$ Skin metastases $\cdot$ Small cell carcinoma

\begin{abstract}
Objectives: To report a rare case of small cell carcinoma of the prostate with unusual skin metastasis. Clinical Presentation and Interventions: A 60-year-old was evaluated for difficulty in urinating. Abdominal computed tomography scans revealed a prostatic mass invading the surrounding tissues and multiple perirectal, periprostatic, para-aortic and pericaval lymph nodes. Needle biopsy specimens showed both small cell carcinoma and adenocarcinoma. He was treated with combination chemotherapy: cisplatin and etoposide and bilateral orchiectomy. After six cycles of the chemotherapy, disease progressed and the patient did not respond to salvage therapy; hence, palliative care was instituted. During the follow-up, papillary lesions were observed in the scrotal skin; biopsy showed metastatic small cell carcinoma. Conclusion: Small cell carcinoma of the prostate is an aggressive disease with a highly metastatic potential; but skin metastases are very uncommon. It has poor prognosis despite therapy. Management resembles that of small cell carcinoma of the lung.
\end{abstract}

Copyright $\odot 2008$ S. Karger AG, Basel

\section{Introduction}

Prostate cancer is the second leading cause of cancer deaths in men; approximately $95 \%$ of prostate carcinoma is adenocarcinoma [1]. Small cell carcinoma of the prostate (SCCP) is rare and occurs only in about $0.5-2 \%$ of patients with prostate cancer. Adenocarcinoma usually accompanies SCCP [1]. The histogenesis of SCCP is not precisely known. According to one hypothesis, SCCP is derived from the malignant transformation of normal prostatic neuroendocrine cells [2]. Another hypothesis postulates that SCCP is derived from multipotential stem cells of the prostatic epithelium $[2,3]$. Due to the nature of the totipotent basal cells of the prostate, SCCP may also develop from conventional adenocarcinoma of the prostate [3]. Based on a previous report [4], 47\% of patients with SCCP present with recurrence of conventional adenocarcinoma, and $17.7 \%$ presented with combined adenocarcinoma. SCCP is aggressive and usually metastatic at diagnosis $[4,5]$; however, metastases to skin are rare.

\section{Case Report}

A 60-year-old man was admitted with polyuria, constipation, fatigue and difficulty urinating for 1 month. On digital rectal examination, there was an enlarged and irregular prostate; there were no other abnormalities on the rest of the physical examination. Standard laboratory analyses including serum prostate-spe-
Yesim Yildirim

Baskent University Department of Medical Oncology

Fevzi Cakmak Caddesi 12, Sokak 7/5

TR-06490 Ankara (Turkey)

Tel. +90 312212 0434, Fax +90 312212 7572, E-Mail dryesimyildirim@yahoo.com 
cific antigen were normal but serum creatinine was mildly elevated. Abdominal computed tomography (CT) scans revealed an enlarged prostate mass $(7 \times 6 \times 8 \mathrm{~cm})$ invading the rectum, seminal vesicle and bladder, and multiple perirectal, periprostatic, para-aortic and pericaval lymph nodes. Histopathological diagnosis of prostate adenocarcinoma (with Gleason score $5+4=$ 9) and small cell carcinoma were made by needle biopsy. The adenocarcinoma component of the tumor was seen focally. Small cell component of the specimen stained positive for chromogranin and synaptophysin. Thoracic CT showed enlarged mediastinal lymph nodes. A positron emission tomography/computerized scan following administration of fluorine-18 fluoro-2-deoxy-glucose showed uptake in the prostate and surrounding tissues, and in the mediastinal lymph nodes; no pulmonary uptake was observed. Bronchoscopy was normal; however, histopathological examination of the pulmonary aspirate showed malignant cells, consistent with a neuroendocrine (small cell) carcinoma. Serum neuron-specific enolase (NSE) was $105 \mu \mathrm{g} / \mathrm{l}$.

Combination chemotherapy with cisplatin and etoposide was started. After 1 cycle, a bilateral orchiectomy was performed for androgen blockade. After the third cycle, the level of NSE decreased to $25 \mu \mathrm{g} / \mathrm{l}$; a partial response of the pelvic mass was observed on CT. The 6 cycles of chemotherapy were completed. However, final CT scans showed no further change in the pelvic mass. Oral etoposide was started. One month later, the serum NSE was $120 \mu \mathrm{g} / \mathrm{l}$ and an abdominal ultrasound revealed increase in the size of the pelvic mass. A right nephrostomy tube and J stent were placed for development of bilateral hydroureteronephrosis. Due to progression of the disease, salvage chemotherapy containing of vincristine, adriamycin and cyclophosphamide was begun. After 2 cycles, a deep vein thrombosis developed and CT scan showed progression in the mediastinal lymph nodes. Chemotherapy and palliative treatment was instituted. After 1 month, the patient was admitted with bleeding papillary lesions on the scrotum. Biopsy of these lesions was consistent with metastatic small cell carcinoma (fig. 1). He died before treatment for skin metastasis. The death occurred 11 months after the initial diagnosis.

\section{Discussion}

SCCP is a rare entity. The natural history is similar to that of small cell carcinoma of the lung (SCCL), with aggressive course and early widespread metastases to the visceral organs. The most common sites of metastases are bones, regional and distant lymph nodes, the liver, lungs, bone marrow, soft tissues and brain [4]. However, skin metastases are uncommon and have been presented in only a few reports $[5,6]$.

The morphology of SCCP is also similar to that of SCCL in that a high mitotic index, vascular invasion and necroses are frequent findings. The prevalence of neuroendocrine cells in the prostate has been correlated with higher-grade malignancy and poor prognosis [3]. For this reason, the immunohistochemical diagnosis of SCCP is crucial when determining treatment. The histogenesis of

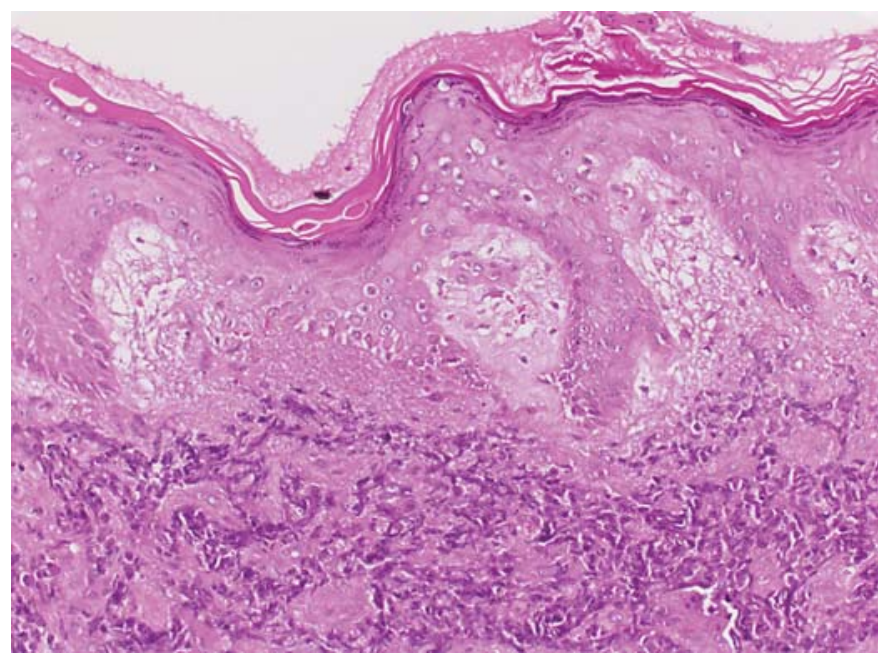

Fig. 1. Metastasis of SCCP into the skin (HE).

SCCP is not clear; the most accepted hypothesis is that it arises from totipotential stem cells of the prostate that differentiate into either epithelial or neuroendocrine carcinomas [6]. This is supported by the fact that in approximately half of patients with SCCP, the malignancy is diagnosed as a recurrence of adenocarcinoma of the prostate [7]. Given that in many patients recurrent adenocarcinoma of the prostate is never rebiopsied, the true prevalence of SCCP is not known [3]. Histological reevaluation of resistant conventional prostate adenocarcinoma may be useful in diagnosing small cell differentiation and changing the treatment modality.

The most common immunohistochemical markers used to diagnose SCCP are NSE, chromogranin, synaptophysin, CD-56 and TTF-1 [4]. In our patient, the level of serum NSE was very helpful. Elevated serum PSA levels can be detected if tumor contains a large amount of adenocarcinoma component. In our case, because of the tiny amount of adenocarcinoma component of the tumor, serum PSA level was within normal limit. Various hormones also have been revealed immunohistochemically; these include ACTH (30\%), seratonin (50\%), gastrin (50\%), vasoactive intestinal peptide (100\%), bombesin (50\%), antidiuretic hormone (50\%) and somatostatin (33\%) [4]. In the serum calcitonin and ACTH are detected most frequently $[3,8]$. Therefore, paraneoplastic syndrome may be observed in some patients.

Because of the rarity of SCCP, there is no standard treatment modality; treatment is similar to that of SCCL. Recommended chemotherapy regimens consist of vincristine, doxorubicin and cyclophosphamide, or etopo- 
side and cisplatin with or without doxorubicin $[6,9]$. Gemcitabine, docetaxel and carboplatin also have been used in studies, and good benefits have been seen with tolerable adverse effects [9]. In the current case, orchiectomy was performed to treat the adenocarcinoma. No common opinion exists on androgen blockade. One patient with SCCP cured by prostatectomy has been reported [10]. However, SCCP usually presents with distant metastases and is therefore not appropriate for surgery [4]. There is no standard recommendation for radiotherapy. However, for local control, some centers advocate concurrent radiotherapy with chemotherapy [11].

\section{Conclusion}

Due to widespread metastatic pattern, oncologists should be vigilant about uncommon sites of metastases of SCCP. The histopathological evaluation of hormonerefractory prostate carcinoma should be made carefully so that the most appropriate treatment is chosen.

\section{References}

1 Yashi M, Terauchi F, Nukui A, Ochi M, Yuzawa M, Hara Y, Morita T: Small-cell neuroendocrine carcinoma as a variant form of prostate cancer recurrence: a case report and short literature review. Urol Oncol 2006;24: 313-317.

-2 Wenk RE, Bhagavan BS, Levy R, Miller D, Weisburger W: Ectopic ACTH, prostatic oat cell carcinoma, and marked hypernatremia. Cancer 1977;40:773-778.

$\checkmark 3$ Palmgren JS, Karavadia SS, Wakefield MR: Unusual and underappreciated: small cell carcinoma of the prostate. Semin Oncol 2007;34:22-29.

4 Papandreou CN, Daliani DD, Thall PF, Tu SM, Wang X, Reyes A, Troncoso P, Logothetis CJ: Prostate cancer with small-cell morphology: an immunophenotypic subdivision. Scand J Urol Nephrol 2005;39: $455-463$.
5 Gupta RK, Naran S: Fine needle aspiration cytology of cutaneous and subcutaneous metastatic deposits from epithelial malignancies. An analysis of 146 cases. Acta Cytol 1999;43:126-130.

6 Aygun C: Small cell carcinoma of the prostate: a case report and review of the literature. Md Med J 1997;46:353-356.

7 Rubenstein JH, Katin MJ, Mangano MM, Dauphin J, Salenius SA, Dosoretz DE, Blitzer PH: Small cell anaplastic carcinoma of the prostate: seven new cases, review of the literature, and discussion of a therapeutic strategy. Am J Clin Oncol 1997;20:376-380.

-8 Sim SJ, Glassman AB, Ro JY, Lee JJ, Logothetis CJ, Liu FJ: Serum calcitonin in small cell carcinoma of the prostate. Ann Clin Lab Sci 1996;26:487-495.
9 Aoki H, Ishidoya S, Ito A, Endoh M, Shimazui T, Arai Y: Experience of the treatment with gemcitabine, docetaxel, and carboplatin (GDC) chemotherapy for patients with small-cell carcinoma of the prostate. Int J Urol 2006;13:1254-1258.

10 Bolton DM, Chiu ST, Clarke S, Angus D: Primary small cell carcinoma of the prostate: unusual modes of presentation. Aust N Z J Surg 1994;64:91-94.

11 Asmis TR, Reaume MN, Dahrouge S, Malone S: Genitourinary small cell carcinoma: a retrospective review of treatment and survival patterns at The Ottawa Hospital Regional Cancer Center. BJU Int 2006;97:711715 . 